\title{
Hermeneutics by the Living
}

\author{
Anton Markoš
}

Received: 20 January 2010 / Accepted: 22 March 2010 /Published online: 13 August 2010

(C) Springer Science+Business Media B.V. 2010

In being presented in play, what is emerges. It produces and brings to light what is otherwise constantly hidden and withdrawn. Someone who can perceive the comedy and tragedy of life can resist the temptation to think in terms of purposes, which conceals the game that is played with us.

H.-G. Gadamer 1975, 112

We no longer stand separate from creation, but rather are situated at its centre.

A. Weber, this volume

Because different factors may be 'most important' in the evolution of different groups, a universal criterion for delimiting fundamental, cohesive evolutionary units does not exist.

Mishler and Donoghue 1982, 495

The chapters of this volume can be seen as being overarched by a single topic: that of the dance, play and self-presentation of the living. One pillar of the arch is rooted in the chapter by A. Koubová, who speaks about living appearances not pointing towards anything yet also revealing meaning. Its second pillar presents the image of singing humpback whales, graciously flipping their huge "wings" while levitating above the oceanic abyss (D. Martinelli). The arch is punctuated by such topics as psychophysical dualism, body, linguistic metaphors of life, mimicry and interpretation.

Why complicate the fermentation occurring at the borderland of life sciences and humanities by introducing hermeneutics? After all, semiotics has already colonized the field, and biosemioticians of different "denominations" flourish at their annual meetings. ${ }^{1}$ Is not, after all, hermeneutics but an older and almost abandoned branch

\footnotetext{
${ }^{1}$ Gatherings in Biosemiotics, organized yearly by the International Society for Biosemiotics.

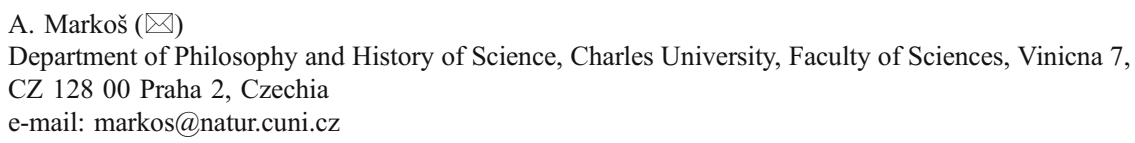


of the art of understanding? Not at all: in the humanities both doctrines continue to develop vigorously. ${ }^{2}$

It is not our goal to retell the long history of hermeneutics, the art of understanding. However, a few words are probably in order. Perhaps the first "boom" it experienced was in Latin antiquity (Cicero, Quintilianus), when it became important to (re)interpret old texts, especially juridical ones, to cope with contemporary needs and goals. On the one hand the ambiguity of the written word (verba) required that the meaning intended by the author (voluntas) be deciphered; on the other there was the need to bring it "home" (oeconomia), to interpret it in terms of equity and the decorum of the time (see, e.g., Eden 1997).

With Christianity, this rhetorical tradition grew into the need to interpret Holy Scripture-to overcome the obscurities of texts written long ago, in foreign languages, and for different communities. Centuries of patristic tradition testify to the immensity of this task. The last two centuries have seen the "secularization" of hermeneutics and, at the same time, its transformation from a technique of interpretation into philosophy. Such efforts are aimed at the extraction of meaning, the appropriation of the text here and now, independently of its historical connotations: "The aim of all hermeneutics is to struggle against cultural distance and historical alienation. Interpretation brings together, equalizes, renders contemporary and similar. This goal is attained only insofar as interpretation actualizes the meaning of the text for the present reader." (Ricoeur 1981, 185) This appropriation may even proceed via play, and the whole question of texts and their interpretation retreats into the background, highlighting even more life and its self-presentations: "The movement of playing has no goal that brings it to an end; rather, it renews itself in constant repetition. [...] Play is really limited to presenting itself. Thus its mode of being is self-presentation. But self-presentation is a universal ontological characteristic of nature. We know today how inadequate are conceptions of biological purpose when it comes to understanding the form of living things. So too it is an inadequate approach to ask what the life function and biological purpose of play is. First and foremost, play is self-presentation" (Gadamer 1975, $104 \&$ 108).

The "play" of interpretation may, of course, take more "serious" forms which aspire to broaden the scope of our understanding of the world and our place in it, as in the hermeneutics of M. Heidegger and H.-G. Gadamer. We are then confronted with the hermeneutic circle, with others, with language, with finality, etc. "Of course the reader before whose eyes the great book of world history simply lies open does not exist. But neither does the reader exist who, when he has his text before him, simply reads what is there. Rather, all reading involves application, so that a person reading a text is himself part of the meaning he apprehends. He belongs to the text that he is reading. The line of meaning that the text manifests to him as he reads it always and necessarily breaks off in an open indeterminacy. He can, indeed he must, accept the fact that future generations will understand differently what he has read in the text". (Gadamer 1975, 335). Or in the words of Ricoeur (1981, 56): "Thus arises

\footnotetext{
${ }^{2}$ Only one point is enigmatic for people coming from science as I am: both research traditions behave as if they had no intersections, nothing in common. They make few references to each other (with some exceptions in U. Eco and J. Deely), and employ no common nomenclature. If hermeneuticians speak about, say, the hermeneutic circle, they don't mention the semiotic spiral, and vice versa - and the baffled scientist seeking enlightenment remains in suspense.
} 
understanding-but not yet as a fact of language, writing or texts. Understanding too must be described initially, not in terms of discourse, but in terms of the 'power-to-be'. The first function of understanding is to orientate us in a situation. So understanding is not concerned with grasping a fact but with apprehending a possibility of being. We must not lose sight of this point $[\ldots]$ : to understand the text, we shall say, is not to find a lifeless sense which is contained therein, but to unfold the possibility of being indicated by the text. Thus we shall remain faithful to the Heideggerian notion of understanding which is essentially a projection or [...] a projection with a prior being-thrown". Aspects of such allusions are touched on by Markoš and Faltýnek in this volume.

The main question remains, of course, whether all this tradition applies to human beings only, or whether it admits of expansion to the whole realm of life. Is the Book of Nature accessible only to human beings, or to all denizens of our biosphere? The philosophers quoted above deal only with human affairs. Is it legitimate for biologists to take inspiration from their efforts and take a further step, or will such work attract the label of "mere" metaphor? At this moment the issue remains undecided.

Before I introduce the contributions in this volume, let me undertake a short digression into the history of biohermeneutics. Priority belongs to the St. Petersburg Seminar on Theoretical Biology, where the term has been used since 1972. V. Chebanov, one of the founders, characterizes the aims of the movement on the webpages Biosemiotica Slavica as follows ${ }^{3}$ :

"The biologist explicitly or implicitly faces the hard task of representing his results in a form appropriate for this knowledge to fit in the culture, since modern Western culture has practically no means to treat the Living without missing its specific properties. This idea brought about the Seminar's interest in the culturological aspects of biology, such as the relations between the activity of the biologist, his personality, and the cultural context.

As a fruit of the analysis of the biomorphal means of knowledge representation, a whole conception of "biocentrism" was developed, involving cultural orientation to Life (as opposed to the orientation to the non-living, "physicalism", and to man, "anthropocentrism", predominant in European culture). One of the "preserveislands" of biocentrism in culture, namely biological systematics, is often in the scope of discussions during the Seminar's sessions. When the phenomenon of Life is regarded more broadly, that is when the forms of life other than biological are taken into consideration, Life proves to be the basic notion for a more general conception: "vita-centrism".

The school worked in isolation during the Soviet era, and its priorities were somewhat different from those of the Western world (it is symptomatic that in their

3 (downloaded Oct 11, 2009; in similar lines, see, e.g. Chebanov 1999). 
articles one finds very few references to, say, Gadamer, Heidegger, or Ricoeur, the principal figures in hermeneutics over recent decades). As can be recognized even from the quotation above, the main concern of the group is the "hermeneutics of the living", i.e. the ways in which we, human beings, interpret life. Above all, this "sociology of biology" is fascinated with classification and sorting according to various criteria, i.e. taxonomy in its broadest sense: some articles are seemingly obsessed by complicated classification tables and refinements. The principal question is "How is it possible that we, people, are able to distinguish things against the background of nature?" The article by A. Oskolski in this volume illustrates the prolific output of this line of thinking.

Another inspiring topic developed by the school is the enlogue, "a quasidialogue taking place in quasipersonal situations [like] ... between a living being and a sensible being (e.g. a biologist) - the interaction is not verbal, though obviously generates some information in the sensible being" (Chebanov 1999, 215). The third topic (out of many) is the strange-looking - at least to me-notion of separating body and life. Life can be embodied not only into what we would call a "living being"-like a plant, bacterium, or animal-but also into the body of a city, nation, population. This "vitacentric" perspective as they call it has some advantages: yes it is possible to treat a city as a living being with its own metabolism, external appearances, even self presentation (lights in the night). But it can look strange indeed in the context of contemporary science of life, where life is always understood as bodily life, not as a kind of spirit entering the body from outside.

And here I add a comment by A. Oskolski: "Certainly, the concepts of enlogue and 'vitacentrism' are very good examples to demonstrate the ways of thinking developed in Chebanov's seminar. Nevertheless, these concepts were not widely accepted even within the members of this seminar. Probably, the most important trait of Chebanov's school was the intensive training in 'taxonomy in its broadest sense' with cultivation of the yearning for refiniments of minor differences between the meanings of words, terms, metaphors, etc."

I admit that when we in Prague started-inspired by phenomenology-using expressions like "biohermeneutics" or "hermeneutics by the living", we had no idea of the existence of the Russian school. After all, our approach was not concerned with how human beings interpret life, but with how life interprets itself, its being in the world (Markoš 2002; Markoš et al. 2009). We started asking whether contemporary phenomenology could provide an alternative to the analytical and reductionist science of biology. If so, it would be worth trying to overcome the strict anthropocentrism of Heideggerian and Gadamerian hermeneutics. A lucky combination of philosophers and biologists of various specializations, all of them with interests in quite esoteric areas of biology (like Portmannian self-presentation; various forgotten authors like Weismann or Driesch; Darwin and his clash with his peers, etc.), glimpses perspectives on phenomena that are not often discussed. The leading figure of the Prague group is Z. Neubauer, developing his eidetic biology with the central concept of likeness. The reader can get an idea of the state of art from Markoš et al. (2009); in this volume it is represented by contributions from K. Kleisner, A. Koubová, and A. Markoš \& D. Faltýnek. These, and also the rest of contributions, fall into the category of "hermeneutics by the living". The principal 
question is: will it ever be possible to "go-along-with" a living being and ascertain what its "worldview" or even "umwelt" looks like? D. Martinelli poses the question by referring to the famous essay by T. Nagel (1981) What is it like to be a bat? (or a Martian, for that matter); why not take the inspiration from here? Nagel says "The fact that we cannot expect ever to accommodate in our language a detailed description of Martian or bat phenomenology should not lead us to dismiss as meaningless the claim that bats and Martians have experiences fully comparable in richness of detail to our own. It would be fine if someone were to develop concepts and a theory that enabled us to think about those things; but such an understanding may be permanently denied to us by the limits of our nature" (Hofstadter and Dennett 1981, 395).

In his reflections on the article, D.R. Hofstadter states (Hofstadter and Dennett 1981, 413): "The one thing that Nagel seems not to have acknowledged in his article is that language (among other things) is a bridge that allows us to cross over the territory that is not ours. Bats don't have the idea of 'what it is like to be another bat' and don't wonder about it, either. And that is because bats do not have a universal currency for the exchange of ideas, which is what language, movies, music, gestures, and so on give us. These media aid in our projection, aid us in absorbing foreign points of view. Through a universal currency, points of view become more modular, more transferable, less personal and idiosyncratic."

So is there no hope? We can "go along with" human beings of different cultures, languages, and epochs, but do there exist means to go along with other living beings, and even more important do they themselves command such a means? Our authors (and many others) claim that without the "universal currency" of language a living being has no access to beings and cannot benefit from its experience in order to plan the future or perform polysemic communication instead of sending only signals.

There is a hope, however. It lies not in denying such specifically human achievements as conceptual language, the invention of the realm of transcendence, oral and written tradition and history, etc. But such human novelties tend to overshadow previous layers from which they get their nourishment, layers we share with other beings. We, the authors of this volume, share the opinion that all living beings abound in properties such as the ability to recognize symbolic cues (signals and even signs), i.e. they are able to interpret their being in the world. This leads us to the view that bodily experience with self and with others points to phenomena like being-itself, autopoiesis, self-expression and self-presentation, interpretation and even creating of symbolic inscriptions (such as, for example, strings of "characters"), as well as co-existence within a community. Living beings thus negotiate even their own development into the future, into the "adjacent possible" (Kauffman 2000). Autopoiesis and being-together (including its historical dimension, evolvingtogether, which has occurred incessantly from the beginning of life) mark two poles of the realm in which living beings know their way, and interpret their situation by means we humans brand using words like semiosis, interpretation, explication, and invention. This volume presents some examples, facets and insights into how to enter that immense field.

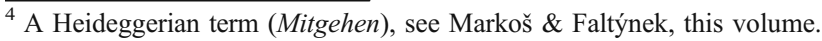


To the contents of the volume:

Alice Koubová points towards what she recognizes as the "bio-cartesianism" of contemporary phenomenology; she suspects that its protagonists (e.g. H.-G. Gadamer) are unable to break the mind-body problem-contrary to what they claim. A purely human quality is highlighted and taken as primary in their work. Koubová pleads for a shift in attention towards the animal, and one way of going along with an animal is represented by artistic work, and especially dance.

Whereas Koubová can do without subjectivity, Andreas Weber highlights the subjectivity of "the other" and approaches the topic from the point of view of autopoiesis: an organism is an embedded cognition. Living beings are above all concerned with themselves; they recognize values, and they display, by body language (as in Kliková, but from a different perspective), their innerness (the "eloquence" of the body). Weber denies the validity of the genocentrism of contemporary biology and takes genes not as instructions but as mere allusions for the living being.

The contribution by Anton Markoš and Dan Faltýnek raises yet another question: can we learn more about life by taking inspiration from the properties of natural languages? This question opens an avalanche of inquiry into the character of language, addressing for example the differences between formal and natural languages, written language, speech, and the thesaurus of language, "languaging" as a mode of existence and, again, the question of whether living beings are languagelike and if so in what sense. (Remember, the exceptional position of humans is not to be challenged.)

Does a taxon, e.g. species, exist independently of human insight, like e.g. a culture? Do members of a taxon recognize their belonging to such a species-culture? Or is classification introduced only from outside, i.e. by human taxonomists? In other words, what do we mean under "reality" of taxa? Alexei Oskolski treats these questions by supposing that taxons do exist, yet it is not an easy task to answer the question of how we, human beings, are able to distinguish and classify them. This is especially so when some taxa are "more real than others"-like nations, cultures, styles. It needs an experienced taxonomist to decide the boundaries. Taxonomy is, then, positioning frames on the realm of the living, from outside, but somehow it seems that the realm is not passive: it is inventing and providing the necessary cues.

Examples of the kinds of cues involved, and of how living giving make them apparent to others, are discussed from different angles in papers by Karel Kleisner, Timo Maran, and Dario Martinelli. Kleisner cultivates Portmannian biology and studies the innerness of living beings as revealed by their external appearance. Maran focuses on the existence and activity of the imitating organism in the world where similarity and iconic sign relations are possible. Finally Martinelli, inspired by Nagel's question "What it is to be a bat?", asks what the animal perceives and understands and how can we know about these things.

One note in conclusion: what is lacking from this volume, which the editor considers a significant failing, are articles about ontogeny and evo-devo. It is not that potential authors were not contacted, but rather that the editor was unable to 
persuade any of those he contacted to contribute. Introducing the topic into the biohermeneutic agenda remains, therefore, a debt for the future.

Acknowledgement My work on this volume was supported by the project of the Czech Ministry of education MSM 0021620845.

\section{References}

Chebanov, S. V. (1999). Biohermeneutics and hermeneutics of biology. Semiotica, 127, 215-226.

Eden, K. (1997). Hermeneutics and the rhetorical tradition. Chapters in the ancient legacy and its humanist reception. New Haven: Yale University Press.

Gadamer, H.-G. (1975). Truth and method (2nd ed.). London: Continuum.

Hofstadter, D. R., \& Dennett, D. C. (Eds.). (1981) The mind's I. Fantasies and reflections on self and soul. New York: Penguin Books.

Kauffman, S. (2000). Investigations. New York: Oxford University Press.

Markoš, A. (2002). Readers of the book of life. Oxford: Oxford UP.

Markoš, A., Grygar, F., Hajnal, L., Kleisner, K., Kratochvíl, Z., \& Neubauer, Z. (2009). Life as its own designer: Darwin's origin and western thought. Springer.

Mishler, B. D., \& Donoghue, M. J. (1982). Species concepts: a case for pluralism. Systematic Zoology, 31, 491-503.

Nagel, T. (1981 [1974]). What is it like to be a bat? In Hofstadter \& Dennett (Eds.), The mind's I. Fantasies and reflections on self and soul (pp. 391-403). New York: Penguin Books.

Ricoeur, P. (1981). Hermeneutics and the human sciences. Cambridge: Cambridge University Press. 